\title{
Developing Primary School Students' Formal Geometric Definitions Knowledge by Connecting Origami and Technology
}

\author{
Budinski Natalija ${ }^{{ }^{*}}$, Zsolt Lavicza ${ }^{2}$, Kristof Fenyvesi ${ }^{3}$, Dragica Milinković ${ }^{4}$
}

\author{
${ }^{1}$ Petro Kuzmjak School, SERBIA \\ 2 Johannes Kepler University, AUSTRIA \\ ${ }^{3}$ University of Jyväskylä, FINLAND \\ ${ }^{4}$ University of East Sarajevo, BOSNIA AND HERZEGOVINA \\ *CORRESPONDENCE: $\square$ nbudinski@yahoo.com
}

\begin{abstract}
In this paper, we present opportunities with the uses of origami and technology, in our case GeoGebra, in teaching formal geometric definitions for fifth-grade primary school students (1112yrs). Applying origami in mathematical lessons is becoming to be recognized as a valuable tool for improving students' mathematical knowledge. In previous studies, we developed origami and technology activities for high-school mathematics, but we wanted to explore if such approach would work in primary school as well. For this reason, we chose a flat origami model of the crane and we used this model to introduce students to basic geometrical notions and definitions, such as points, lines, intersections of lines and angles. To complement mathematical ideas from paper folding we also employed mathematical software GeoGebra, to further ideas and extend students' mathematical toolkits. However, to be able to use software, students would already need basic conceptions of geometric definitions and then the use of the software clearly add to solidifying their knowledge. We believe that the combination hands-on activities and technology could contribute to discovery learning and enhancing students' understanding of geometric definitions and operations.
\end{abstract}

Keywords: origami, GeoGebra, formal geometric definitions

\section{INTRODUCTION}

Origami and folding are attracting increased attention in a wide-range of scientific disciplines to understand, solve and contribute to a variety of problems in these fields. Simple and ordinary activities, such as folding animal and plant figures, is being applied in the scientific research due to the solid mathematical foundations laid for origami and folding (Lang, 2009). The connection between origami and mathematics was established by setting origami axioms which differentiate creases (Alperin \& Lang, 2006; Huzita, 1989, 1992; Lang, 2003). Origami axioms enabled constructions of cube roots and solutions of quadratic, cubic and quartic equations, and several other scientific discoveries. For example, paper folds known as Miura-ori are suitable for designing robots, mini surgical devices or space satellites and solar panels (Nishiyama, 2012). All these facts are convincing reasons that origami is becoming an effective educational tool.

Following the innovations in science, origami also started to become recognized in the teaching mathematics (Boakes, 2009; Budinski et al., 2018; Fenyvesi et al. 2014; Robichax \& Rodrigue, 2003). There are evidences that highlight that use of origami helps students to develop better understanding of elementary geometry and it can be very helpful in upgrading their knowledge in that field (Golan, 2011). Use of origami

Article History: Received 9 September $2019 \bullet$ Revised 23 October $2019 \bullet$ Accepted 23 October 2019

(C) 2020 by the authors; licensee Modestum Ltd., UK. Open Access terms of the Creative Commons Attribution 4.0 International License (http://creativecommons.org/licenses/by/4.0/) apply. The license permits unrestricted use, distribution, and reproduction in any medium, on the condition that users give exact credit to the original author(s) and the source, provide a link to the Creative Commons license, and indicate if they made any changes. 
brings more benefits to students in process of learning geometry than traditional methods, because motivation and creativity are taking the most significant part. Origami helps students in better recognition and definition of geometrical terms and shapes. It is achievable due to the process of folding and observing shapes during those activities. Most often, origami activities are connected to geometry lessons, but origami can be a great support in explaining many other mathematical concepts and developing various skills, such as problemsolving abilities, logical thinking or 3D perception (Boakes, 2009). Origami application in mathematical lessons could be beneficial for improving students' mathematical knowledge as well (Boakes, 2015; Fiol et al., 2011; Gur \& Kobak-Demir, 2017).

Recent findings in origami shows that origami could be favorable for both, children and adults. It has positive influence on concentration, logic development and children discipline, while diminish stress and hypertension among adults (Miller, 2007; Shalev, 2005; Shumakov \& Shumakov, 2001; Zarei \& Malekian, 2015). One of the studies, conducted on a small group of 7 to 11 years old children, revealed the fact that activities related to origami stimulate interaction of right and left-brain hemisphere and development of intelligence (Motaweh et al., 2014). There are strong recommendations for origami trainings in order to develop children's creative, motor and intellectual abilities. It is an excellent developmental exercise, with many possibilities, from very simple to very complex folds that enables child to develop at his own pace and interest, continually upgrade its own skills (Shumakov, 2000).

\section{BULDING MATHEMATICAL KNOWLEDGE WITH THE ORIGAMI AND TECHNOLOGY}

This study outlines primary school experiences (11-12 years old) of developing formal geometrical definitions knowledge by using origami and technology. We found that the application of the approach was challenging, due to students' limited mathematical knowledge and technological experience. Prior to this study we were developing origami connected to technology approach in order to develop mathematical knowledge on secondary school level of education (15-19 years) (Budinski, 2015; Budinski et al., 2018; Fenyvesi et al, 2014a, 2014b).

The obtained results encouraged us to apply the approach in teaching mathematics to younger students, roughly in age of 12 when qualitative change in the cognitive development of children happens (Piaget, 1972). In this age most of the children transition from the stage of concrete operations to the stage of formal operation, which means that children are enabled to understand logical relationship between different elements without relying on the concrete content. It can be said that this period is crucial for educational advancement (Susac et al., 2014). That means that the learning environment and approaches in this period of students' cognitive development should be treated with the great attention. Students in the fifth grade already have an intuitive knowledge of certain geometrical objects, but in the fifth grade the mathematical knowledge in the field of geometry need to be more formal. Building up the formal mathematical knowledge in the young age is not an easy task, since not all students have developed ability of formal thinking yet (Piaget, 1972).

\section{Participants and Research Methods}

In this paper, we outlined our observation in developing formal geometrical definitions knowledge by connecting origami and technology in the fifth grade of primary school "Petro Kuzmjak" in Serbia with 35 students. During two joints classes, we used origami and GeoGebra as a shortcut to quick acquaintance with basic geometrical definitions and formal mathematical language.

In order to fulfill the aims, we conducted descriptive and qualitative study. We prepared lessons plans on basic geometry and systematically noted situations and comments during the implementation. During the implementation of the lesson plan, we made notes on students' activities, comments, and results, according to the plan of actions.

\section{The Aim of the Study}

The aim of the study was to observe the following problems: organization of an origami and technology supported lesson in order to teach formal geometrical definitions and evidence collection of impact that this approach would have in the process of constructing geometrical knowledge in the fifth grade of primary school The content of learning comprised of recognizing geometrical objects, naming them properly, defining them with formal mathematical language, knowing mathematical properties of objects, and calculating with them. 


\section{Phases of Classroom Activities}

During the lessons, we followed two Serbian curricular objectives (Službeni glasnik, 2017). The first objective was based on the proposal that students in the fifth grade must be familiar with notions such as points, rays, lines, line segments and planes. Also, they need to know how to find the area and circumference of given shapes, and to understand notions of symmetry. The second objective was to teach students how to use educational software.

Beside the lesson plans, there were also instructions provided in printed and video forms and administered assessments for students learning. The process had several phases of activities, such as preparation and introduction, folding paper by following instructions, exploring mathematical objects in origami creases, and learning how to use technology. During the activities students not only revised their mathematical knowledge and adopted formal geometrical definitions, but also learned how to use educational software, which would help them in generating new knowledge in the future. Lessons began with the introduction aimed to raise students' motivation and describing the purpose of the lessons to students. We explained connection to previous lessons and their prior knowledge was taken into consideration as well. Students learned some of the content, but in the different, informal and traditional approach. The next step was dedicated to the task that involved the process of making origami cranes. We designed this task somewhat challenging and to help enhancing students' knowledge in geometry, since the flat origami models consists numerous mathematical contents. In sum, we used simple origami model, the crane, to convey geometrical concepts to students.

\section{The Educational Software of Choice: GeoGebra}

In order to enrich origami activities and introduce students' skills with technology, we included educational software GeoGebra to the teaching process. GeoGebra is one of the most widely used mathematical software and studies showed that its proper uses could enhance students' learning processes by engaging them in open problem solving, mathematical modeling, creations and experimental work (Bu et al., 2012; Zilinskiene, 2014).

GeoGebra is an opensource and free software, popular among teachers and students in Serbia and worldwide due to its simple interface, advanced features, availability on a wide range of devices such as computers, tablets or smartphones (Zilinskiene, 2014). GeoGebra enables visualization of mathematical and scientific concepts, making these contents approachable, and comprehensive for learners, even in primary schools (Boo \& Leong, 2016; Bulut et al., 2016; Zilinskiene, 2014; Zilinskiene \& Demirbilek, 2015).

\section{RESULTS OF THE APPLICATIONS OF ORIGAMI AND GEOGEBRA IN GEOMETRY LESSON}

\section{Origami Classroom Activities}

Our investigation started with finding suitable origami activities that will connect fifth grade mathematics and be supportive enough for introducing technology. After analyzing curriculum requirements and the science of origami, we decided to start the lesson with folding origami cranes which are among the most recognizable origami figures. The classical origami crane is part of flat origami model group. Those models can be pressed (Hull, 2002; Scheneider, 2004) without additional creases.

According to Lang (2003) flat paper folding follows the rules that can be described mathematically. There are four main principles of flat origami and two are used to support developing students' formal mathematical knowledge. The first one is the two-color ability meaning that flat origami crease patterns can be colored in two colors without intersecting the same color. The second is Maekawa's theorem (Justin, 1986) where the number of mountain and valley folds differs by two (Justin, 1986). Described in mathematical language, mountain folds are convex folds, while valley folds are concave (Hull, 2003). Folding origami crane and handson activities were organized to help students to understand geometrical notions and definitions, such as points, lines, intersections of lines and angles, but also to find mathematical properties of flat origami figures. Lessons started with the introduction and giving instructions to students. We explained the goals of lessons, then students started working on foldings with standard printer papers. Also, two types of the instructions were prepared to support students independent work: video and paper-printed instructions (see Figure 1). In Figure 1, we can see paper-printed origami instructions for folding a crane. 


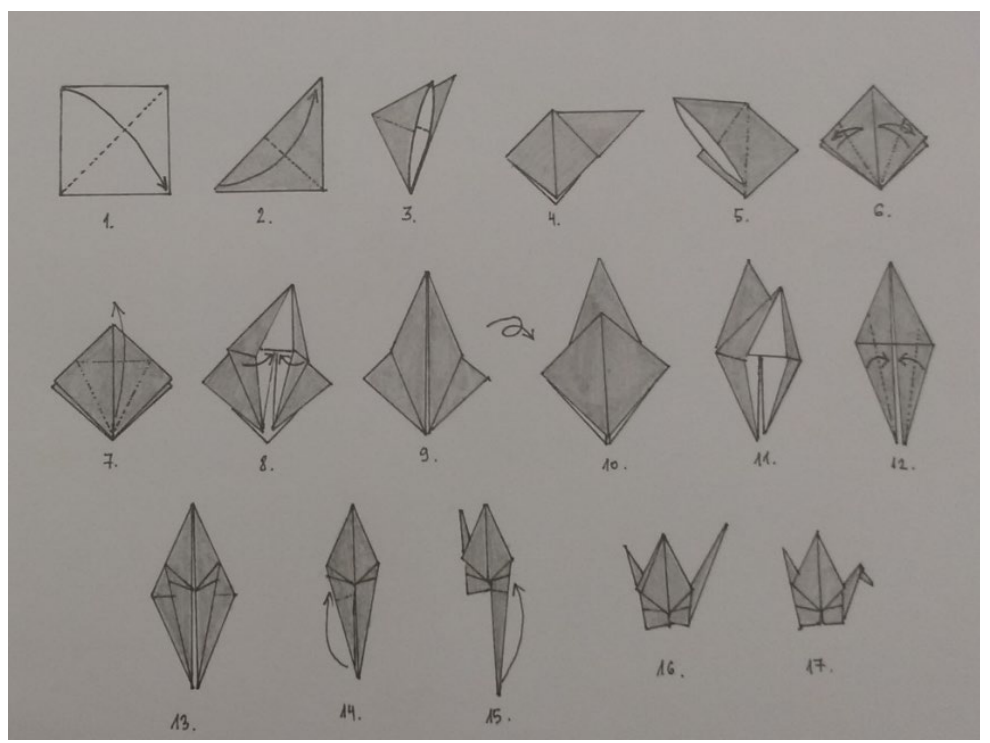

Figure 1. Printed origami crane instructions for students

Several folding steps contain hidden or transparent mathematical concepts, which were analyzed or revealed throughout the hands-on activities. The first and basic geometrical exercise for students was to provide a square shape paper from a rectangular shape printer paper. That required repetition of the square definition and reminding students of what kind of polygon square is, and how to obtain a square from a rectangular shape of paper. After successfully obtaining square shape of papers, students were encouraged to follow instructions and proceed with the folding process.

While following folding instructions, students were constantly reminded about mathematical terms that occurred during the process. They were stimulated with questions highlighting mathematical notions. For example, the first step of folding required folding by diagonals, which was suitable point to define segments, a diagonal as a segment that connects two opposites vertices of a polygon. In these points, students were also introduced with the concept of the perpendicular line. They got a task to find all perpendicular lines that were resulted by previous folding, which was also a point where we analyzed the notion of an angle. Students were motivated to discover a mathematical definition of an angle. Also, during one of the folding steps, students needed to fold the paper in half, which was easy for students because students were familiar with fractions, especially with such basic as a half. As the paper needed to be folded into half by horizontal and vertical middle lines, students noticed further divisions and quarters. Further folding steps were technical, so students were encouraging to proceed with folding in order to obtain desired figure.

It had to be noticed that several students needed assistance because they found difficult to follow the instructions. We encouraged students to help each other and we also supported collaborative learning. While analyzing folding activities, we observed that seven students (20\%) finished folding the crane without the help of the teacher, following instructions by themseles. The majority of students (72\%) succeeded to finish their models with assistance or teacher's help, while only three students (8\%) did not finish the folding process as they found it very difficult. In the discussion of what makes a crane folding difficult, students mentioned several obstacles: difficulty to connect visual representations in the instructions with their own actions, they rarely or never practiced origami and paper folding, or that they were not skilled in folding and with handson activities. Especially, students found difficult the part when 2D object was transformed to 3D object by folding. The benefits that students highlighted the enjoyment of the folding process, a relaxing way to learn geometry, and that they had an opportunity to "make geometrical" notions making understanding and learning mathematics easier. After finishing the folding process of the crane, students unfolded object and analyzed the papers in mathematical contexts. In Figure $\mathbf{2 a}$ and $\mathbf{2 b}$, we can see two color ability of a crane crease pattern as a result of students' work.

During this activity students analyzed unfolded crane patterns, solving the following tasks: counting mountain and valley folds and exploring Maekawa's theorem (Justin, 1986), also trying and attempting to color the crane crease pattern with two colors. They were also examining geometrical shapes, intersections, points and angles resulted by the foldings. 


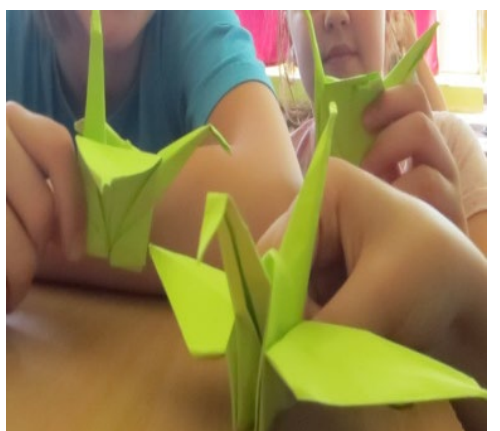

(a)

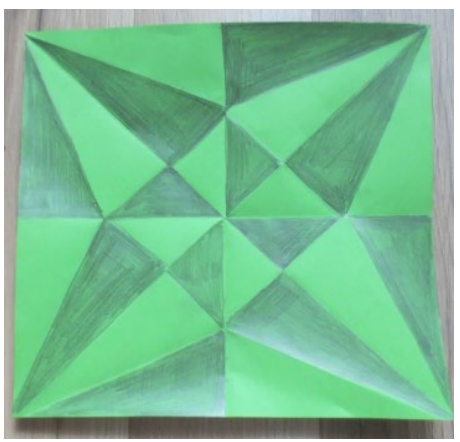

(b)

Figure 2. a and b) Student's work of application on origami principles based on mathematics

Table 1. Successfulness in making origami and GeoGebra model

\begin{tabular}{lcc}
\hline & $\begin{array}{c}\text { ORIGAMI MODEL OF CRANE } \\
\text { (number of students (\%)) }\end{array}$ & $\begin{array}{c}\text { GEOGEBRA MODEL OF CRANE } \\
\text { CREASE PATTERN } \\
\text { (number of students (\%)) }\end{array}$ \\
\hline Finished independently & $7(20 \%)$ & $12(34 \%)$ \\
\hline Finished with the assistance & $25(72 \%)$ & $21(60 \%)$ \\
\hline Unfinished & $3(8 \%)$ & $2(6 \%)$ \\
\hline
\end{tabular}

\section{GeoGebra Classroom Activities}

During the previous activities, origami was used to remind students of previously learned geometrical notions and to introduce new ones. Revising basic geometrical notions and teaching students formal geometrical definitions were necessary for the next task, which was leading to the learning how to use GeoGebra for these activities. The origami task was used to clarify how geometrical notions are defined and represented, since unknown geometrical notions could confuse students during the technology learning process. This lesson was students' first encounter with GeoGebra and we hoped that after the introduction students would learn basic functions of GeoGebra and be able to use it in their future work.

The first step of GeoGebra activities was the introduction of the GeoGebra interface and its commands. Students were instructed to create a GeoGebra crease pattern of origami crane, and color it with two colors, similarly as it was done with the physical object, shown in Figure 2 (left side). In order to do that, students needed to use the following GeoGebra commands and learn how to implement them: regular polygon and number of vertices, midpoint, segment and diagonal, perpendicular line, intersection of two segments, highlight polygon and different colors usage. Also, students needed to learn how to use zoom in and zoom out in GeoGebra and navigate through the screen. During the work with GeoGebra, students showed great interests in the constructions. They found some commands very easy, such as zooming and moving pointer, or drawing points and segments. The task that required coloring the polygon was more complicated and required more time. Students noticed that it was easier to color the physical model than virtual one. It can be noticed that $12(34 \%)$ students finished the task without assistance, 21 (60\%) students needed help during the completing task and two (6\%) students did not finish the task.

\section{ORIGAMI AND TECHNOLOGY COMPLEMENTING MATHEMATICAL KNOWLEDGE}

We aimed to gain insights on students geometry learning with origami and technology. Results of the successful task completion with origami and GeoGebra are shown in Table 1. It can be noticed that students work more independently in GeoGebra than with paper folding. In the percentages, $34 \%$ vs $20 \%$ completed the task independtly with GeoGebra and origami respectively. Our interviews suggested that students are more familiar with technology in their everyday life than manual or hands-on activities, thus could work with virtual objects more easily. Accordingly, GeoGebra work was smoothly and took considerably less time to finish than paper folding. In addition, students had less and more simple questions from teachers in the GeoGebra activity. We were also aware that origami is not a common mathematical activity, so students needed to get used to that approach and that could also have an influence on their success in solving the tasks. 
Table 2. Constructing a square in origami and GeoGebra activities

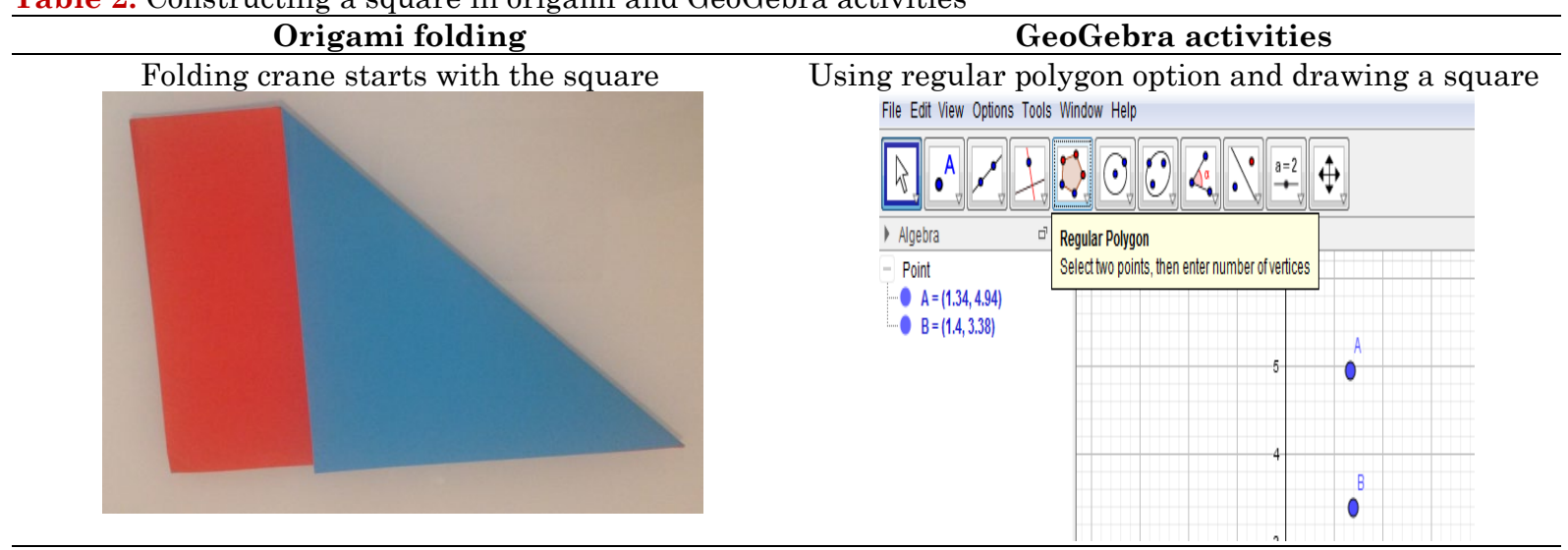

Table 3. Constructions of segment and diagonals of a square in origami and GeoGebra activities

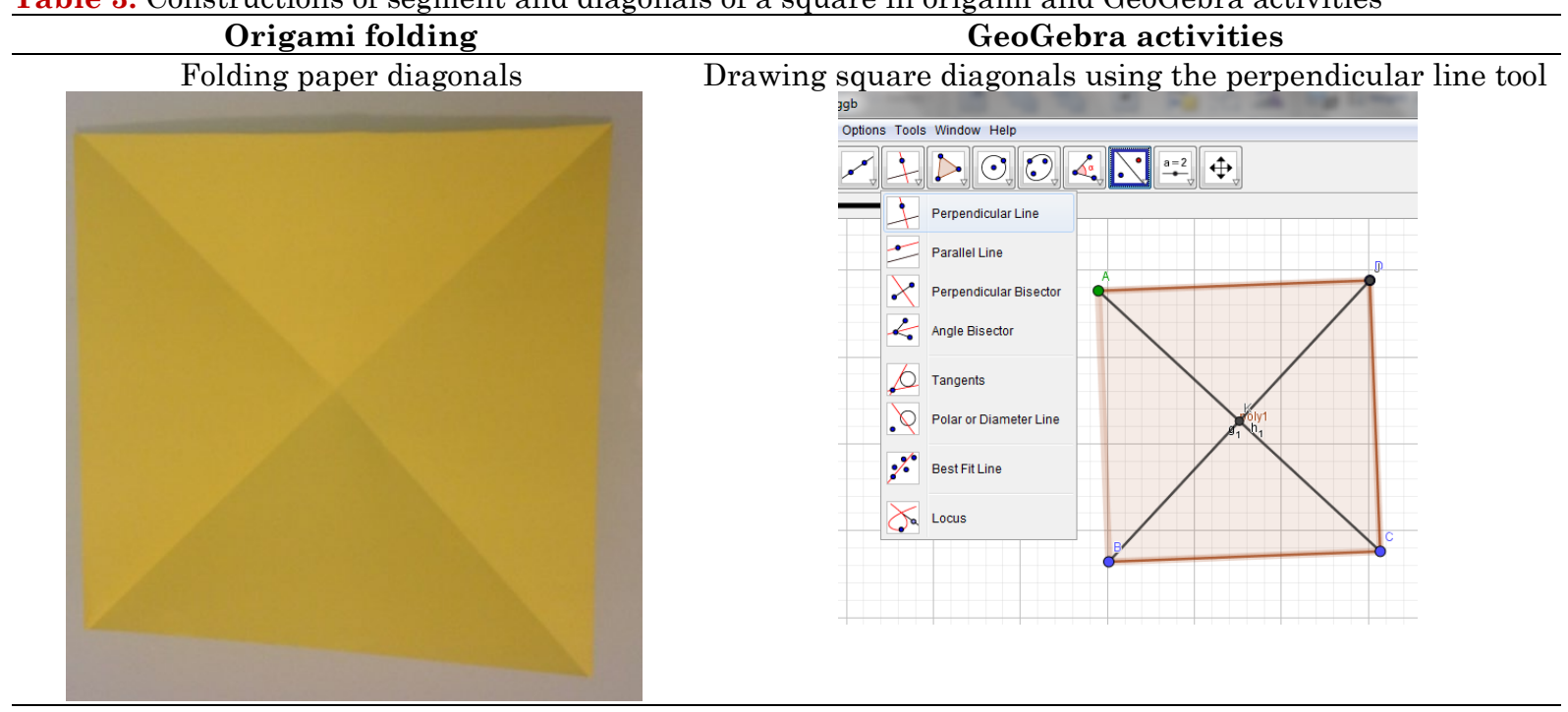

During the process students had an opportunity to notice relationships between physical and virtual representations of geometrical objects and diversify their knowledge. They were familiar with the mathematical contents, because they acquired geometrical notions and formal definition during the origami activities, basically their task was to find the necessary GeoGebra commands and implement them for their work. Tables 2, 3, 4 and 5, respectively, shows how mathematical content, origami folding and GeoGebra activities were connected during the lesson and how they complemented each other. The connection between tasks and knowledge can be seen, and how the transfer from one to another activity was made. Table 2 shows how students revised the features of square during folding process and the origami activities. Their task was to construct a square with folding and with using a GeoGebra commands. Both required knowledge of the formal definition of square and its properties.

Table 3 shows how the terms such as segments, diagonals and perpendicular lines be learned through origami and GeoGebra activities. In order to fold square shaped papers diagonally students needed to know what the diagonal is, and that lead them to the formal definition. In order to construct diagonals of a square by using GeoGebra, they needed to know that the diagonals of a square are perpendicular.

In Table 4, we can see how origami and GeoGebra were used to revise geometrical notions such as middle points and lines, angles, but also students had an opportunity to observe symmetries. Besides geometrical definitions, students analyzed parts of geometrical objects through their connections to fractions. 
Table 4. Constructions of middle points and lines, angles and observation of symmetry and fractions in origami and GeoGebra activities

\section{Origami folding}

Folding paper in half following the middle line and connecting middle points

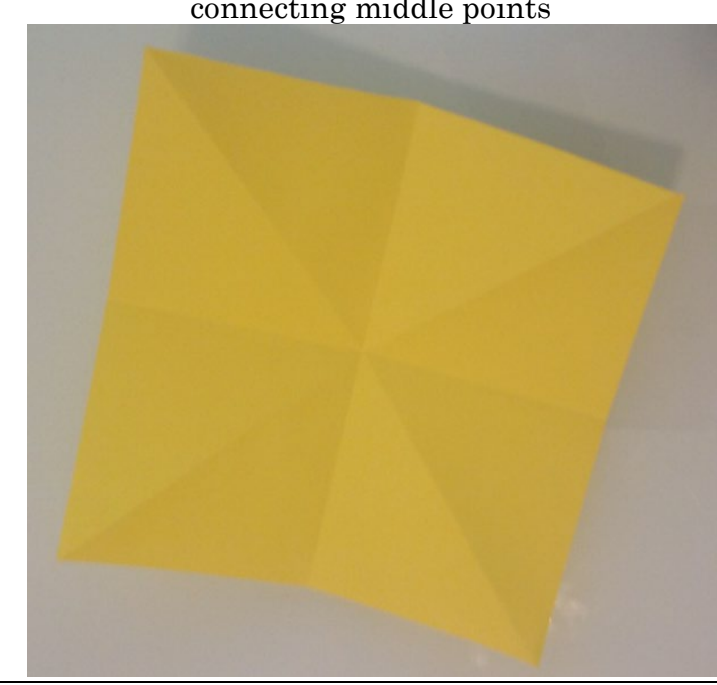

\section{GeoGebra activities}

Drawing a middle line using midpoint and segment option

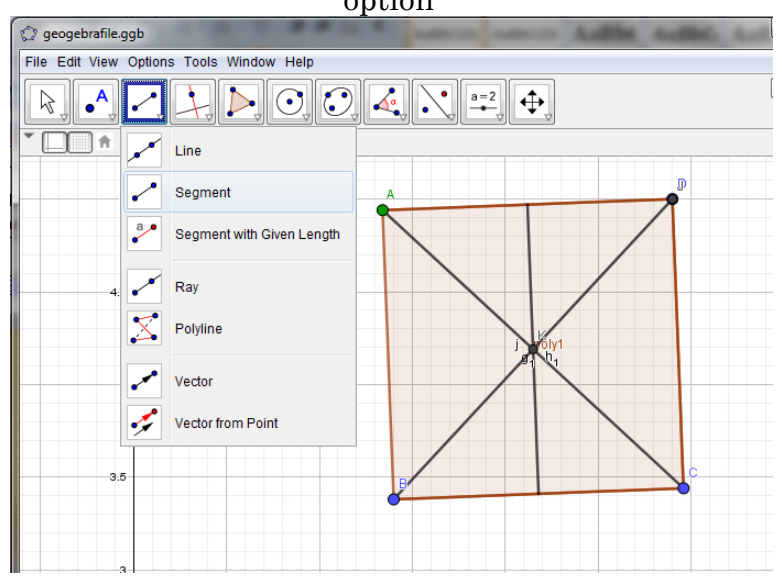

Table 5. Exploring property of two-colors theorem with origami and in GeoGebra

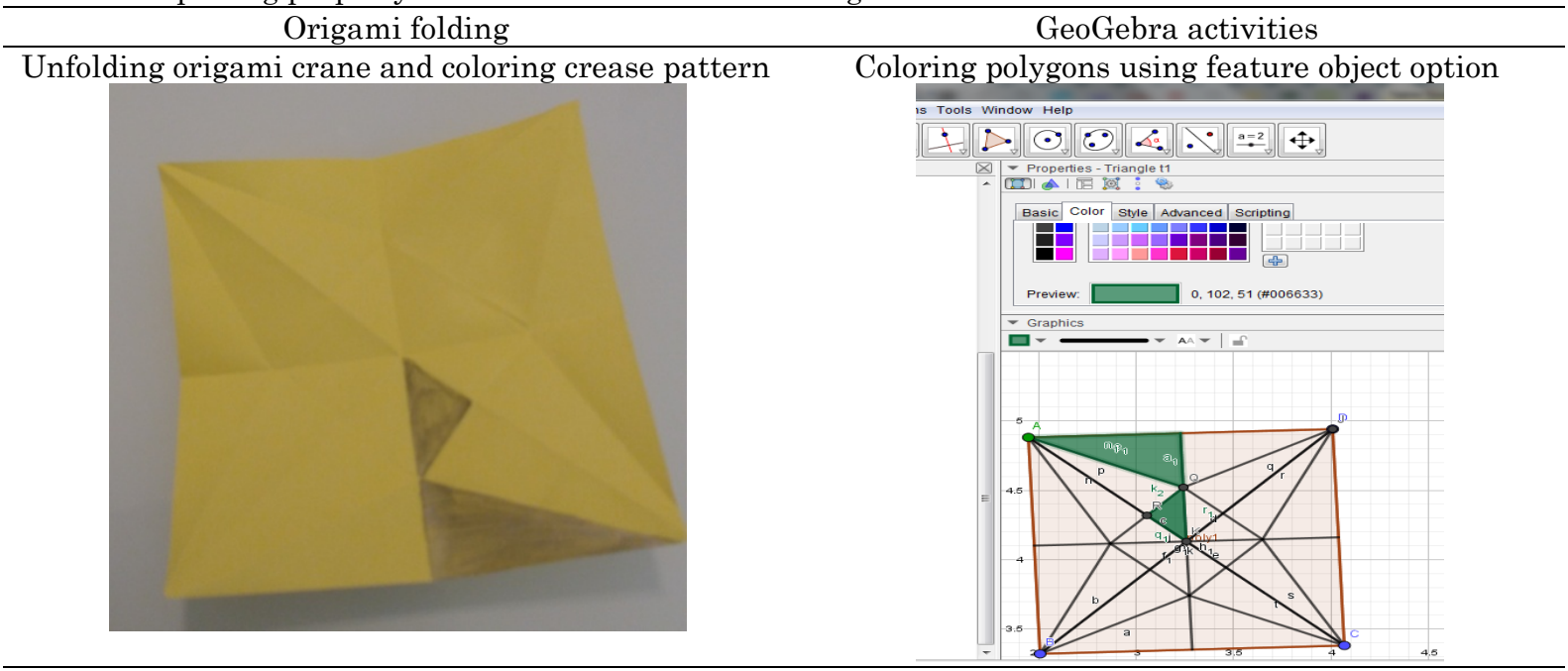

Table 5 shows how the advanced mathematical concept in this study, the property of two colors ability of flat origami objects was presented in the physical model, but also virtually in GeoGebra.

Facilitated discussions during all activities encouraged students to identify and familiarize different geometrical shapes and their attributes. Questions that were used to extent students thinking were gradually introduced from easy to hard. The easy questions were related to the identifying and naming geometrical shapes. Crease patterns helped students to illustrate abstract concepts, such as line, segment or length. The average level of questions was related to the comparison and computation of geometrical shapes features such as length or size, while advanced questions were related to symmetry. These activities were interesting to the students since the connection of physical and virtual representations of the same objects were highlighted. Students liked to use colors in connections to the mathematical concepts and develop strategies of coloring.

\section{DISCUSSION}

During this study we developed strategies of combining different approaches to develop formal mathematical knowledge of primary school students. This approach created a learning environment enabling 
the emergence of formal geometrical definitions and mathematical content and it fostered motivation and enjoyment for students in learning the topics. Students were motivated by the demonstration of the usefulness of geometry in everyday life, its connection to origami, and the applications of technology in the process.

Activities were based on Serbian curriculum requirement, but with origami and GeoGebra we added novelties and introduced contemporary science and technology to the fifth-grade students. Activities in the study shown that students, even young students can be challenged with advanced concepts, such as two-colors theorem or Makeawa's theorem or with the use educational software (Justin, 1986). To achieve this goal, the approaches in the classroom needed to be different from traditional methods. By combining origami and technology we managed to find a way to introduce advanced concepts. On the one hand, origami has features of a game, it is pleasing, entertaining and exciting activity, involving emotions, but on the other hand it is educational, learning-by-doing activity which is helpful in developing academic goals related to mathematics. Even simple folding of a paper into half or by a diagonal is a mathematical exercise, where the concept of a half or diagonal can be illustrated respectively. Hands-on activities of origami provided literal manipulation of mathematical concepts that students learned. Obstacles in the process of two-dimensional square paper transformation to three-dimensional crane figure helped in the process of developing spatial visualization, which is identified as essential elements in studying geometry (Battista, Wheatley, \& Talsma, 1982).

Origami helped in developing abstract thinking and developing formal geometrical knowledge, which is important in mathematical education. Origami in our lessons provided active method of research, where students progressed gradually. Some of these results were already observed by Golan (2011), but in our case we upgraded origami activities to teach students basics of educational technology. Once students clearly understood geometrical contents, it was easy for them to manipulate the required technology.

Additional mathematical exercises occurred during the use of GeoGebra, where we encouraged students to investigate and reason mathematically. Mathematical content was emphasized in each activity, even though students were not aware of it all the time. Activities provided meaningful learning environments where students were constantly in the situation of investigation new formal mathematical knowledge and connecting it with their informal mathematical knowledge gained during the previous years of their education. We paid attention to the presentation aspects and formulation of the concepts, where we focused on both learning mathematics and interdisciplinary contents.

Our study provided results on how the combination of different approaches could assists students to independently discover mathematical notions in more formal ways. It was done by identifying geometrical objects resulted by folding papers and exploring their properties. Activities supported interaction of different representations which we found valuable in the process of learning geometry. In our research, we overcome the challenges of the primary level education limits by careful planning and adjusted activities. In the planning phase, we had valuable prior experience from other projects and from researchers in the field (Boakes, 2009; Budinski et al., 2018; Fenyvesi et al., 2014a, 2014b).

Results of our study could be used in various classrooms to built up students' knowledge of geometry based on understanding and linked to the experience, which is making mathematical content relevant to them. Origami and GeoGebra could support the creation of meaningful learning environments and help students to acquire formal mathematical knowledge at first as well as improve their motor and digital competences. This approach motivated students to work on mathematics and contributed not only to learning, but also to the connection of different disciplines. Our work in this field is continuing in similar projects and hope we can contribute to the advancement of teaching mathematics and connecting physical and digital activities in education.

\section{ACKNOWLEDGEMENT}

The paper was written during the exchange program supported by CEEPUS in period September 2018January 2019 at Johannes Kepler University in Linz.

\section{Disclosure statement}

No potential conflict of interest was reported by the authors. 


\section{Notes on contributors}

Natalija Budinski - Teacher of mathematics at Petro Kuzmjak School in Serbia and PhD student at University of East Sarajevo in Bosnia and Herzegovina.

Zsolt Lavicza - Professor in STEM education research methods at Johannes Kepler University, Austria.

Kristof Fenyvesi - Postdoctoral researcher at the University of Jyväskylä, Finland.

Dragica Milinković - Associate professor at University of East Sarajevo, Bosnia and Herzegovina.

\section{REFERENCES}

Alperin, R., \& Lang. R, (2006) One-, Two-, and Multi-fold Origami Axioms. Origami Fourth International Meeting of Origami Science, Mathematics and Education. A K Peters Ltd.

Boakes, N. (2009). Origami instruction in the middle school mathematics classroom: Its impact on spatial visualization and geometry knowledge of students. Research in Middle Level Education Online, 32(7), $1-12$.

Boakes, N. (2015). Crossing borders with origami in mathematics education. Paper presented at the 2015 annual meeting of the American Educational Research Association. Retrieved [2018], from the AERA Online Paper Repository. https://doi.org/10.1080/19404476.2009.11462060

Boo, Y. J., \& Leong, K. E. (2016). Teaching and Learning Geometry in Primary School Using GeoGebra. Paper presented at $21^{\text {st }}$ Asian Technology Conference in Mathematics, at Pattaya, Thailand.

Bu, L., Mumba, F., Wright, M., \& Henson, H. (2012). Teaching mathematics using GeoGebra: integrating pedagogy and content in teacher education. In: D. Martinovic, D. McDougall, \& Z. Karadag (Eds.), Technology in Mathematics Education: Contemporary Issues (pp. 91-115). Santa Rosa, California: Informing Science Press.

Budinski, N. (2015). Origami and Technological Prospectives in Mathematical Education. T1.1010. https://doi.org/10.3390/isis-summit-vienna-2015-T1.1010

Budinski, N., Lavizca Z. \& Fenyvesi, K. (2018). Ideas for using GeoGebra and Origami in Teaching Regular Polyhedrons Lessons. K-12 STEM Education 4(1), 297-303.

Bulut, M., Akcakin, H. U., \& Kaya, G. (2016). The Effects of GeoGebra on Third Grade Primary Students' Academic Achievements in Fractions. International Electronic Journal of Mathematics Education, 11(2), 347-355.

Fenyvesi, K., Budinski, N., \& Lavicza, Z. (2014a). Two Solutions to an Unsolvable Problem: Connecting Origami and GeoGebra in a Serbian High School. In G. Greenfield, G. Hart, \& R. Sarhangi (Eds.), Proceedings of Bridges 2014: Mathematics, Music, Art, Architecture, Culture (pp. 95-102). Phoenix: Tessellations Publishing.

Fenyvesi, K., Budinski, N. \& Lavicza, Z. (2014b). Problem Solving with Hands-on and Digital Tools: Connecting Origami and Geogebra in Mathematics Education, The Closing Conference of the project Visuality \& Mathematics, Belgrade, Serbia, September, 17-19, 2014, pp. 25-38.

Fiol, M. L., Dasquens, N., \& Prat, M. (2011). Student Teachers Introduce Origami in Kindergarten and Primary Schools: Froebel Revisited. In P. Wang-Iverson, R. J. Lang, \& M. Yim (Eds.), Origami 5: Fifth international meeting of origami science, mathematics and education (pp. 151-165). New York: CRC Press. https://doi.org/10.1201/b10971-16

Fraenkel, J., \& Wallen, N. (2006). How to Design and Evaluate Research in Education (6th ed.). Boston: McGraw Hill.

Georgeson, J. (2011). Fold in Origami and Unfold Math. Mathematics Teaching in Middle School, 16(6), 354361.

Golan, M. (2011). Origametria and the van Hiele Theory of Teaching Geometry. Origami, 5, 141-150. https://doi.org/10.1201/b10971-15

Gur, H., \& Kobak-Demir, M. (2017). Teaching via Origami: The Views of Secondary Mathematics Teacher Trainees. Journal of Education and Practice, 8(15), 65-71.

Hull, T. (2002). The Combinatorics of Flat Foldis Survey. The Proceedings of the Third International Meeting of Origami Science, Mathematics, and Education, 29-38. https://doi.org/10.1201/b15735-5

Hull, T. (2003). Counting mountain-valley assignments for flat folds. Ars Combinatoria, 67. 
Huzita, H. (1989). Axiomatic Development of Origami Geometry. Proceedings of the 1st International Meeting of Origami Science and Technology, 143-158.

Huzita, H. (1992). Understanding Geometry through Origami Axioms. COET91: Proceedings of the First International Conference on Origami in Education and Therapy, British Origami Society, 37-70.

Justin, J. (1986). Résolution par le pliage de l'équation du troisième degré et applications géométriques. L'Ouvert - Journal de l'APMEP d'Alsace et de l'IREM de Strasbourg (in French), 42, 9-19.

Lang, R. (2003). Origami and Geometric Constructions.

Lang, R. (2009). Mathematical Methods in Origami Design. Bridges 2009: Mathematics, Music, Art, Architecture, Culture, 13-20.

Miller, Y (2007). A Phenomenological Exploration of Brief Art Therapy Through Folding Two-dimensional Drawings Created by an Adult Population, Faculty of the College of Nursing and Health Profession (PhD Thesis), Drexel University.

Motaweh, D., Fukuyama, H., \& Issa, A. (2014). Effectiveness of the proposed training program on attention and working memory for children with special needs in Saudi Arabia. Life Science Journal, 11(8), 461474.

Nishiyama, Y. (2012). Miura folding: Applying origami to space exploration. International Journal of Pure and Applied Mathematics, 79(2), 269-279.

Piaget, J. (1972). Intellectual evolution from adolescence to adulthood. Hum. Dev. 15, 1-12. https://doi.org/10.1159/000271225

Shalev, H. (2005). Origami in Education and Therapy. Theragam.com New York's Educational Therapeutic Origami Program for Children and Adolescents.

Shumakov, K., \& Shumakov, Y. (2001). The folding: A method of bilateral development: Based on the art of origami. Retrieved from www.oriland.com

Shumakova, E. R. (2000). Functional interhemispheric asymmetry of a brain in dynamics of bimanual activity at children 7-11 years old at origami training (Ph.D. thesis). Publishing house of the Rostov State University.

Službeni glasnik RS, (2017) br. 6/13.

Susac, A., Bubic, A., Vrbanc, A., \& Planinic, M. (2014). Development of abstract mathematical reasoning: the case of algebra. Frontiers in Human Neuroscience, 8, 679. https://doi.org/10.3389/fnhum.2014.00679

Zarei, A., \& Malekian, F. (2015). The Role of Teaching Based on Art Therapy with Origami Method in the Decrease of Ultra-Active Pre-Elementary School Children's Impulse Disorder of Kermanshah Township (in Rotational Disobedience and Disorder Parameters). Journal of Educational and Instructional Studies in the World, 5(1), 56-62.

Zilinskiene, I. (2014). Use of GeoGebra in Primary math education: a theoretical approach, Lietuvos Mathematikos Rinkinys, 55, 73-78.

Zilinskiene, I., \& Demirbilek, M. (2015). Use of GeoGebra in Primary Math Education in Lithuania: An Exploratory Study from Teachers' Perspective. Informatics in Education, 14(1), 127-142. https://doi.org/10.15388/infedu.2015.08 